\title{
Relocating Gender Stereotypes Online: Critical Analysis of Sexist Hate Speech in Selected Social Media
}

\author{
Stanley Elias, Universitas Airlangga \\ Nubar Gurbanova, Universitas Airlangga
}

\begin{abstract}
The ever-increasing use of social media in African countries is celebrated as it has provided people with more spaces for dialogue and individual expressions. Whereas such ever-increasing of the accessibility and use of social media spaces offers users with freedom and democratic paradigms to comment, opine and debate on social, economic and political agenda, it has also resulted to increasing forms of sexist hateful speech. In so doing social media spaces have also changed the nature of communication, as a result, sexists appear to locate their discriminative voices in the new online spaces unlike in the traditional outlets and mainstream forums. This form of sexist hate speech incites gendered stereotypes of whom women often receive the extremes of the malpractices because of prevalence of patriarchal social set ups in most African societies. In most cases in Africa, sexist hate speech will be used as a weapon of gender-based violence means to bully women into silence and to maintain men's privileges. By using Content Analysis and Critical Discourse Analysis approaches, this study analyzed the linguistic clues of the sexist hate speech in Facebook and Instagram social networks. On the basis of selected open accounts of Tanzanian public figures and celebrities, this study particularly observed and interrogated on how language of the users embeds ideological and social construct in order to perpetuate and exacerbate gender inequality. The study partly examined sexist hate speech in the selected Russian social media to comparatively study how sexism is construed and perceived in the community.
\end{abstract}

Keywords: gender stereotyping; linguistic clues; sexist hate speech; social media; Tanzania

\section{Introduction}

The ever-increasing uses of social media in African countries in $21^{\text {st }}$ century is celebrated as it has provided people with more spaces for dialogue, individual expressions, and live the lives in general. According to Iginio and Gagliardone (2014), such ever-increasing on the accessibility and the use of social media spaces has offered users with democratic paradigms to talk, comment, opine, and debate on social, economic, and political agenda. This democratic exercise of commenting, opining, and debating has also resulted to increasing forms of sexist hate speech. With the vigorous change of communication traditions that the world and the African continent is now witnessing, the forms of sexist hate speech in online spaces have appeared to mature to greater extent. Iginio and Gagliardone (2014) found out that the new social media outlets have allowed sexists locate their discriminative voices that they couldn't do in the traditional censured media outlets and mainstream forums. Their sexist voices in social media often incite gendered stereotypes of whom women often receive the extremes of all because of the prevalence of patriarchal social set ups in most African societies. In most cases in Africa, sexist hate speech will be used as a weapon of gender-based violence means to discriminate women into silence and maintain men's privileges (Nakitare, 2012; Muendo, 2017). As of the foregoing view, sexist hate speech and its forms fertile to subjugate others, and more importantly to perpetuate and exacerbate gender inequality. While sexist hate speech is maturing in social media in African settings, it is yet not to receive the interest of many scholars. Ezeibe (2015) underlined that hate speech and its forms are at extensive dimension due to poor legal frameworks to combat it and yet remain understudied. In this light, this paper sets out to critically analyze the linguistic clues of the sexist hate speech in Facebook and Instagram social networks. The study particularly analyzes and interrogates on how the language of the users embeds ideological and social constructs that perpetuate and exacerbate gender inequality. 
So far, hate speech is yet to receive agreeable definition by scholars. According to Herz, Kairys, Perry, Racusen, \& Scheppele (2011), Arcan (2013), Ezeibe (2015), and Brown (2017), such contested debates over the definition of hate speech have been fueled by the fluidity of the term and as of its nexus to be the freedom of speech of an individual. Again, it is noted that hate speech is subject to context, culture, and legal interpretations and so does remain elastically conceived among scholars interested in the discussion. Of all the definitions that scholars and legal practitioners, hate speech has been largely conceived on the basis of its intention to insult, degrade, defame, to negatively incite stereotyping, hatred, discrimination or violence against people in virtue of race, ethnicity, nationality, religion, sexual orientation, disability or gender identity (Nakitare, 2012; Brown, 2017; Muendo, 2017; Roiha, n.d.). In the similar view, Peraro (2016) alluded to Snežana Samardžić-Marković's, Director General of Democracy, Council of Europe that engages in the fields which are vital for the sustainability of democracy, clarity to highlight the context in which sexist hate speech can be conceived that;

"Let's be clear from the outset: sexist hate speech is a human rights violation. It is a form of violence against women and girls that feeds into gender-based discrimination. Sexist hate speech presents a serious obstacle to the achievement of real gender equality. [...] There is no acceptable excuse for sexist hate speech, and action is necessary to counter its rise. [...] Free speech and free expression are not "free" if they are hijacked to intimidate, demean, and - ultimately - to try to silence women, subjecting them to hate speech"

As of the above highlight, sexist hate speech is a form of violence against women and girls that perpetuates and exacerbates gender inequality. It is one of the forms of sexism, which promotes ideologies, believes, assertions or acts expressing contempt towards a person, based on her or his sex or gender (Peraro, 2016). As a social phenomenon, sexist hate speech has been fertile in perpetuating gender inequality and in some cases silencing the targeted person (Lei, 2006; Nakitare, 2012; Arcan, 2013; Roiha, n.d.). As a result, sexist hate speech is rampant in every place - online, offline, and other forms of social interaction for the foregoing reasons pointed out. Of a particular note, the true extent of sexist hate speech and its forms is partly hidden by the fact that many targeted women do not report such violence (Peraro, 2016). In addition, Peraro (2016) argued that some groups of women are targeted by sexist hate speech, but every woman and girl is a potential target.

Gagliardone, Patel, and Pohjon (2014), however, observed that due anti-hate speech regulations in offline and other forms social interaction with censorship sexist hate speech and its forms have not been to greater extent than in online spaces. According to Ring (2013), the internet and social media networks have drastically altered the way we get our news, talk to our friends, comment, and debate on our world view. Indeed, internet increases has eroded the barriers of communication and it has granted democratic nature communicating our views, ideas, opinions, and our entire lives. Also, as pointed out earlier, the democratic exercise of commenting, opining, debating, and sharing ideas and information have also resulted to increasing forms of sexist hate speech that propagate gender inequality and hegemonic relationship between men and women in the society. More importantly, sexists have been using internet media to discriminate and stigmatise targets unlike in the traditional media forums. For Peraro (2016), what people comment, debate, and opine which ascribes gender inequality and stigmatisation in social media has its genesis from the cultural norms of the given society. According to Gagliardone, Patel and Pohjon (2014), the forms of sexist hate speech can be disseminated language (short messages), song lyrics, symbols, gestures, art, and images. In the light of this paper, this study analyzes and interrogates on how the language of the social media users embeds ideological and social constructs that perpetuate and exacerbate gender inequality.

\section{Methodology and scope of the study}

The scope of this study includes two social media networks, namely Facebook and Instagram, in the Tanzanian settings. The selected pages and open accounts of Tanzanian public figures and celebrities in the named social media are involved in the study. The choice of the Tanzania's public figures and celebrities (women from media, politics, and entertainment 
industries), is due to the fact that they are potentially highlighted groups that receive sexists comments (stereotypes) and opinions in the social media. According to Gender Equality Unit (2016), every woman and girl is a potential target for online and offline sexist hate speech, but the most likely are women in media, politics, gaming, human rights, and entertainment. Referring to their pages and accounts, the study examine, analyze, and interrogate the comments or what they share about the individual celebrities on the way they signal gender stereotyping. In assessing the data from the selected pages and accounts of Tanzanian public figures and celebrities, Critical Discourse Analysis (CDA, here after) approach is deployed to examine on the way language as a form of social practice embeds ideological constructs that perpetuate gender inequality. Also as of the CDA interest in unravelling the ideology behind certain discourses, this study uses the CDA to interrogate the way on how sexist hate speech signals patriarchal set-ups of the community, which continue to subjugate women over men dominance. According to Van Dijk (2003), discourse plays an indispensable role in the reproduction of ideologies and daily expressions. Expression of our sayings expresses our ideologically-based views, especially as a member of a group. The discourse is both fed from ideologies and is shaped according to the ideology; as well as our ideologies (Van Dijk, 2003).

\section{Sexist hate speech in the social media in Tanzania}

The essence of sexism is rooted on the imposition of double standards that underlie discrimination against women on the basis of sex. Sexism is an ideological component of gender-based violence carried out by patriarchal societies for the purpose of social segregation of women. Such sexist ideological set ups are evidential in all forms of media (Lei, 2006). In Africa, sexism in hate speech is used to mute women when they appear to challenge traditional male roles. In similar trends, sexist and women stereotyping have been in robust increase in social media in Tanzania. For instance, it is manifested through the language the users use in either their statuses or comment section as observed in the following comments;

"We mwanamke ningekushauri umlee mmeo, hustahili hata kdg kusima2 mble ya Watz kuzungumzia siasa"

[English translation]

"You woman, I would ask you to take care of your husband, you don't deserve to stand in front of Tanzania and talk about leadership" (identity hidden) commented on Facebook wall page on the female politician open account"

(Identity hidden) "Jitambue wewe demuuu acha us*nge shika spika tangaza na gari usituchoshe huтиииии"

[English translation]

"Know yourself you lady (casual). Leave your nonsense (derogatory one) else use microphone and a car to ask. Don't trouble us here," which is taken from Instagram account of the media celebrity lady.

Solomon (2006) noted that in almost all media forms in Tanzania, the language that the authors use is pervasively gendered and in either ways it selects or carries ideological constructs of the community. Conversing alike to Solomon in the selected social media, the language is discriminative and biased. Women receive no better treatment in the language they are addressed to. For instance, phrases like "we mwanamke' (you woman), demu (unmarried lady in the very casual way)" address women diminutively with stereotyped roles that they can perform in the community if they are compared to their male.

According to Morna and Mufune (2002), media forms in Tanzania have been representing women in their traditional role as sexually existing being for male or with male defined interest. As pointed earlier, sexism is in some ways combatted in the mainstream media. Trends show that in social media, it has been gaining prominence because of poor policies. Of this stereotyping role of looking women as sexual objects for male and with male defined 
interest, in selected media, women have been ascribed with roles that reflect to please men sexually. For example, in the comments below;

"PUMBAVU WW MALAYA WA KUTUPWA AMAN YETU HAIWEZI KUVUNJWA NAWEWE MUUZA MWILI"

[English translation]

(Identity hidden) "YOU ARE STUPID, A PROFESSIONAL PROSTITUTE, OUR PEACE CANNOT BE DISTURBED BY YOU WHO SELLS THE BODY," taken from Instagram account of the female politician from opposition side.

\section{"Usitupigie kelele nenda kamridhishe mumeo"}

[English translation]

(Identity hidden) "Don't disturb us with your noise, go and satisfy your husband"

In the foregoing comments, women are ascribed with roles that first undermine them in the Tanzanian community. The language ascribes women incapable of anything except to please men and satisfy them sexually. Second, their existence in the community is explained along with men's. They are living is interdependent with men's existence. In so saying, women are appendage of men in everything except sex that they are capable with.

\section{Sexist outside Tanzania: Is there any difference?}

This paper analyzes sexism in some selected pages in the biggest Russian social network named "VKontakte". The male dominant language of the traditional media has made women the target of discrepant, discriminatory language, and hate speech from almost the very beginning. Such a discourse is reproduced in the social media environment through the comments made into the online media contents, and the tone of the hate speech is in fact increasing.

"Brand Analytics" presented the data for the regular active audience of social networks in Russia for May 2017. In the social network, "VKontakte", for the month, recorded 25.722 authors and more than 310.795 messages. The number of posting, commenting authors in "VKontakte" amounted to 25.7 million, they generated 310 million messages. Gender distribution in the network is traditional: $58.4 \%$ of female authors, $41.6 \%$ of men. The main age group was $37 \%$ authors, aged from 25-34 years old. The second largest group is 18-24 years old $(25.7 \%)$.

Russian media actively broadcasts hate speech against women, replicating the worst of prejudices and obsolete clichés. The most widespread tendencies are of sexual objectification (commercialization of the female body and sexuality) and the myth of "natural purpose" (an orthodox-patriarchal view of the place of women in the family and society). According to Judith Butler (1997), the person who uses hate speech is not the author of his/her own words:

"A person is responsible for his/her words, but he/she is not the creator of those words. It quotes only from the predefined vocabulary, the repertoire of the present, the existing racial heritage, a ready-to-use language appropriate for the situation. The person who is perceived as the author of hate speech is actually the product of that saying."

Combating hate speech against women in the media is a struggle for freedom of speech and expression. If women as a social group do not have equal access and adequate representation in the media, it is impossible to speak about freedom of speech seriously. In 2015, the government of the Russian Federation reported on getting the "Sexist of the Year" award by the UN Committee on the Elimination of All Forms of Discrimination against Women. In social media applications such as "VKontakte", Facebook, Twitter, and others, individuals share the hate speech that his/her friends have produced; they see it naturally and do not feel angry, aggressive, or disdainful. For Binark and Bayraktutan (2013), hatred crimes even can be organized by hate speech. 
The materials of the Independent Institute of Communication Studies showed that about 30 percent of Russian citizens do not see anything wrong with intolerant behavior. Several studies on hate speech have been conducted; books and articles on this topic have appeared which shows that in Russian society, there is no tradition of moral condemnation of hate speech (Maria, 2016). That kind of thing is perceived as a norm of political and social life, although it is not quite a pleasant norm. It has been proved that, since ethical norms for self-regulation of mass media in this field have not been developed, besides online social networks, all sorts of hate speech, misogyny, xenophobia is widely spread even in respected socio-political periodicals and especially in television and radio broadcasts.

"Shut your sexist mouth up" public page gathered an audience of 26,000 subscribers, started a page in Instagram and even launched its own website. In this page, women talk about how they encountered sexism, which according to these stories, waiting for them at every turn. Posts are divided into categories, such as sexism in education, advertising, and media.

\section{Conclusion}

The discussion of sexist hate speech in social media is just at infant stage, especially in developing countries. With some studies that have been done so far, sexism in social media is argued to discriminate and marginalize women in all social, economic, and political affairs. In this study, it can be argued that social media spaces have not only changed the nature of communication, but also provided sexists with forum to locate their discriminative voices online. The form of sexist voices incite gendered stereotypes of whom women often receive the extremes of the malpractices because of prevalence of patriarchal social set ups in most Tanzania societies. The language in the social media is pervading patriarchy ideologies and hence continue to subjugate women to continue obeying male dominant system. Outside Tanzania, sexism has shown similar trend whereby women remain the victim of it. Unlike in Tanzania where there are no efforts to combat, in the Russian selected case, there are visible efforts to combat sexist hate speech in the social media.

\section{References}

Arcan, H. E. 2013. Interrupted social peace: Hate speech in Turkish media. The IAFOR Journal of Media, Communication and Film, 1(1), 43-56.

Binark, M. \& Bayraktutan, G. 2013. Ayin karanlik yuzu: Yeni medya ve etik \{The dark side of the moon: New media and ethics \}, Istanbul: Kalkedon Yayınları.

Brown, A. 2017. What is hate speech? Part 1: The myth of hate. Law and Philosophy, 36(4), 419-468.

Dictionary Statement: HateSpeech. Available at https://beta.strelkamag.com/ru/article/vocabulary-hate speech. (Accessed 30 May 2018).

Ezeibe, C. C. 2015. Hate speech and electoral violence in Nigeria. In Two-day National Conference on the.

Gagliardone, I., Patel, A., Pohjonen, M. 2014. Mapping and Analysing Hate Speech Online.

Herz, M. E., Kairys, D., Perry, I., Racusen, S., \& Scheppele, K. L. 2011. Hate speech and the language of racism in Latin America: A Lens for reconsidering global hate speech restrictions and legislation models. University of Pennsylvania Journal of International Law, 32(3), 805-841.

Judith, B. 1997. Excitable speech. A politics of the performative. Routledge.

Lei, X. 2006. Sexism in language, 5(1), 87-94.

Morna, C. and Mufune, J. (n.d.). Media on the a-gender: Audit of the Southern Africa: Declaration on Gender and Development. In DS Media.

Muendo, M. 2017. The options for Kenya as an impending election fues fear of hate speech.

Nakitare, R. 2012. Women in the Crosshairs as Hate Speech Puts African Media under Pressure. Peraro, A. 2016. Seminar Combating Sexist.

Ring, C. E. 2013. Hate speech in social media: An exploration of the problem and its proposed solutions by Caitlin Elizabeth Ring B . A. Dissertasion. University of Colorado, United 
States.

Roiha, O. J. and M. (n.d.). Backgrounds, experiences and responses to online hate speech: A comparative cross-country analysis.

Social Networks in Russia, Summer 2017 Figures and Trends. Available at http://blog.branalytics.ru/sotsialnye-seti-v-rossii-leto-2017-tsifry-i-trendy/. (Accessed 30 May 2018).

Solomon, E. 2006. Women's roles in the media: Attitudes towards gender issues in six Tanzanian. Thesis. University of Tampere International School of Social Sciences, Department of Journalism and Mass Communication, Finland.

Unit, G. E. 2016. Background note on sexist hate speech, 1-10.

Van Dijk, T. 2003. The discourse-knowledge interface. In G. Weiss, \& R. Wodak (eds.). Multidisciplinary CDA. London: Longman, 13-112. 